\title{
Compartilhamento de mídia e preferência eleitoral no Twitter: uma análise de opinião pública durante as eleições de 2014 no Brasil
}

\author{
Arthur Ituassu ${ }^{1}$ \\ Sergio Lifschitz ${ }^{2}$ \\ Leticia Capone $^{3}$ \\ Maria Beatriz Vaz ${ }^{4}$ \\ Vivian Mannheimer ${ }^{5}$
}

Recibido: 2017-03-31

Aprobado por pares: 2017-05-15

Enviado a pares: 2017-04-03

Aceptado: 2017-09-04

DOI: 10.5294/pacla.2018.21.3.9

Para citar este artículo / to reference this article / para citar este artigo

Ituassu, A., Lifschitz, S., Capone, L., Vaz, M. B. y Mannheimer, V. (2018). Compartilhamento de mídia e preferência eleitoral no Twitter: uma análise de opinião pública durante as eleições de 2014 no Brasil. Palabra Clave, 21(3), 860-884. DOI: 10.5294/pacla.2018.21.3.9

\section{Resumo}

Esta pesquisa analisou tweets postados durante o segundo turno das eleições presidenciais de 2014 no Brasil, no intuito de investigar a mídia compartilhada e a preferência eleitoral do cidadão no Twitter. Para tanto, desenvolvemos uma metodologia e aplicamos uma análise manual de conteúdo e sentimento sobre uma amostra de 1129 tweets $(\mathrm{N}=1129)$ publicados

\footnotetext{
orcid.org/0000-0003-4781-1946. Pontifícia Universidade Católica do Rio de Janeiro, Brasil. ituassu@puc-rio.br

2 orcid.org/0000-0003-3073-3734. Pontifícia Universidade Católica do Rio de Janeiro, Brasil. sergio@inf.puc-rio.br

3 orcid.org/0000-0003-3134-6701. Pontifícia Universidade Católica do Rio de Janeiro, Brasil. leticiacapone@aluno.puc-rio.br

4 orcid.org/0000-0002-3791-9841. Pontifícia Universidade Católica do Rio de Janeiro, Brasil. mbrvaz@aluno.puc-rio.br

5 orcid.org/0000-0002-4072-8755. Pontifícia Universidade Católica do Rio de Janeiro, Brasil. vmannheimer@aluno.puc-rio.br
} 
no momento, a fim de identificar qual a mídia compartilhada em cada uma das publicações e a preferência eleitoral expressa no tweet entre os dois candidatos na disputa. Nossos achados reforçam a noção de que há uma predominância do compartilhamento de mainstream media no ambiente das mídias sociais, mas ressaltam também a presença considerável (40\%) do que chamaremos de "mídias complementares", que oferecem conteúdo mais partidarizado durante a campanha. Ao mesmo tempo, ambos os "públicos" constituídos na análise compartilharam a mesma proporção de mídia de mainstream e mídias complementares, o que denota um padrão a ser testado em futuros estudos.

\section{Palavras-chave}

Brasil; eleições 2014; mídias sociais; opinião pública; Twitter (Fonte: Tesaura da Unesco). 


\section{Publicación de medios y preferencia electoral en Twitter: análisis de opinión pública durante las elecciones del año 2014 en Brasil}

\section{Resumen}

Esta investigación analizó tuits publicados durante la segunda vuelta de las elecciones presidenciales de 2014 en Brasil, con el fin de investigar los medios compartidos y la preferencia electoral de los ciudadanos en Twitter. Con este fin, desarrollamos una metodología y aplicamos un análisis manual de contenido y sentimiento sobre una muestra de 1129 tuits $(\mathrm{N}=$ 1129) publicados en ese momento para identificar cuáles eran los medios compartidos en cada una de las publicaciones y la preferencia electoral expresada en el tuit entre los dos candidatos en la disputa. El hallazgo refuerza la noción de que en las redes sociales se comparten predominantemente los principales medios de comunicación, pero resaltan también la presencia considerable (40\%) de lo que llamaremos "medios complementarios", que ofrecen contenido más partidarizado durante la campaña. Al mismo tiempo, ambos "públicos" constituidos en el análisis compartieron la misma proporción de medios principales y medios complementarios, lo que denota un patrón que se deberá probar en futuros estudios.

\section{Palabras clave}

Brasil; elecciones 2014; redes sociales; opinión pública; Twitter (Fuente: Tesauro de la Unesco). 


\section{Sharing Media and Electoral Preference on Twitter: Analysis of Public Opinion during the 2014 Elections in Brazil}

\section{Abstract}

This research analyzed a series of tweets published during the second round of the 2014 presidential elections in Brazil, in order to investigate the shared media and the electoral preference of citizens on Twitter. To that end, we developed a methodology and applied a manual analysis of content and sentiment to a sample of 1129 tweets $(\mathrm{N}=1129)$ published at the time in order to identify which media were shared in each of the publications and the electoral preference between the two candidates expressed in the tweet. Our findings reinforce the idea that mainstream media is predominantly share don social media, but also that there is considerable presence $(40 \%)$ of what we call "complementary media," which offer more partybased content during the campaign. Furthermore, both "audiences" in the analysis shared the same proportion of mainstream and complementary media, which denotes a pattern to be tested in future studies.

\section{Keywords}

Brazil; 2014 elections; social networks; public opinion; Twitter (Source: Unesco Thesaurus). 


\section{Introdução}

Em 26 de outubro de 2014, mais de 100 milhões de brasileiros foram às urnas escolher entre a incumbente Dilma Rousseff, do Partido dos Trabalhadores (PT), e o oposicionista Aécio Neves, do Partido da Social Democracia Brasileira (PSDB). ${ }^{6}$ Todo o segundo turno daquela campanha fora marcado por intensa polarização entre o que seria um candidato mais à direita, Aécio Neves, e uma candidata mais à esquerda, Dilma Rousseff, descendente política do ex-presidente Luiz Inácio Lula da Silva, que governou o Brasil de janeiro de 2003 a janeiro de 2011. Como se não bastasse, a disputa repetia aquela entre os dois partidos - PT e PSDB - em pleitos presidenciais anteriores: 2002, 2006 e 2010. Ao fim, Dilma Rousseff obteve 54501118 ou 51,64 \% dos votos válidos. Aécio Neves, 51041155 ou 48,36\%.

Em meio a esse contexto polarizado entre esquerda e direita no Brasil, resolvemos coletar e analisar tweets publicados durante o segundo turno das eleições de 2014 a fim de identificar a mídia compartilhada em cada uma das postagens e a preferência eleitoral, entre os dois candidatos, expressa no tweet.

Como se sabe, o Twitter se diferencia no mundo das mídias sociais pelo fato de que boa parte de suas mensagens são públicas e curtas, a grande maioria delas aberta para o exame de qualquer pessoa conectada à mídia social, diferentemente do Facebook ou do Google+, por exemplo, nas quais o conteúdo em geral fica mais restrito a públicos específicos. Além disso, os veículos de mídia também estão presentes no Twitter e, ao menos em termos formais, têm suas contas como qualquer usuário. Dessa forma, enquanto estudos de media effects desenvolvem, na maior parte das vezes, uma análise de conteúdo de mídia e de público separadamente, o Twitter apresenta a oportunidade de se analisar público e mídia de modo simultâneo (Vargo, Guo, McCombs e Shaw, 2014).

Ao mesmo tempo, como as mensagens no Twitter são obrigatoriamente curtas, com no máximo 140 caracteres, torna-se recorrente no am-

6 O segundo turno das eleições de 2014 registrou o total de 105542273 de votos válidos. Sobre isso, ver: http:// www.tse.jus.br/eleicoes/estatisticas 
biente o uso de links que acompanham a postagem e apontam o leitor para outro espaço midiático. A nosso ver, a identificação dos links torna possível perceber que tipo de mídia cada público escolhe e compartilha na mídia social, tendo em mente que o Twitter vem sendo percebido como uma importante plataforma mediadora de notícias, como apontam reports recentes (Newman, Levy e Nielsen, 2015; Pew Research Center, 2015; Rosentiel et al., 2015).

Com isso, a nossa expectativa foi averiguar o leque de mídias compartilhadas pelo cidadão no Twitter em ambiente de campanha no Brasil, que tipo de mídia compartilhou e se houve variações de compartilhamento em relação à sua preferência eleitoral. Como aponta a Pesquisa Brasileira de Mídia (Brasil, 2015), o país tem hoje cerca de 100 milhões de usuários, dos quais $75 \%$ têm acesso diário à internet, e $67 \%$ utilizam a web prioritariamente para pesquisar e se informar. O Twitter tem mais de 300 milhões de usuários ativos por mês no mundo, e o Brasil foi, em 2016, o país onde a mídia social obteve seu terceiro maior crescimento em número de usuários. ${ }^{7}$

Nesse sentido, a próxima seção deste artigo discute as questões desta pesquisa em relação à literatura especializada, para, em seguida, apresentarmos a metodologia desenvolvida e os resultados encontrados. Ao fim, algumas discussões são feitas com base nos achados da pesquisa. Em nossa interpretação, os dados demonstram uma penetração ampla das mídias principais (mainstream media) no Brasil em ambos os grupos de eleitores, mas também a presença de um conjunto de mídias que denominamos "mídias complementares”, com uma oferta de conteúdo mais partidarizado durante a campanha.

\section{Sobre as questões}

A literatura especializada já apresenta um conjunto variado e farto de estudos sobre as mídias sociais em contexto eleitoral. Algumas análises discutem o potencial democrático de campanhas desenvolvidas nas mídias digitais

7 Sobre isso, ver: "Brasil tem o terceiro maior crescimento do Twitter em número de usuários" (Folha de S. Paulo). Recuperado em http://wwwl.folha.uol.com.br/tec/2017/02/1861175-numero-de-usuarios-do-twitter-no-brasil-cresce-18-em-2016.shtml 
(Gomes, Fernandes, Reis e Silva, 2009; Ituassu, Capone, Parente e Pecoraro, 2014). Outras procuram averiguar o potencial interativo desse mesmo ambiente para a relação entre os políticos-candidatos e o eleitorado (Vaccari e Nielsen, 2013; Muñiz, Dader, Téllez e Salazar, 2016; Murta, Ituassu, Capone e Rovere, 2017). Alguns autores chegaram inclusive a montar um modelo de previsão eleitoral com dados retirados do Twitter (Tumasjan, Sprenger, Sandner e Welpe, 2010; Oliveira, Bermejo e Santos, 2016). Esta pesquisa, no entanto, não trata especificamente do uso das mídias sociais em campanhas, mas se aproveita do ambiente eleitoral para desenvolver uma análise de opinião pública, seguindo outros trabalhos que ressaltam o potencial das mídias sociais para esse tipo de estudo (Vargo et al., 2014; Vargo, 2011; O'connor, Balasubramanyan, Routledge e Smith, 2010).

Nesse contexto, como afirmado na Introdução, esta pesquisa procura analisar tweets postados durante o segundo turno das eleições presidenciais de 2014 no Brasil, no intuito de averiguar a escolha de mídia e a preferência eleitoral do cidadão no Twitter. Assim, pergunta-se: que fontes midiáticas o cidadão compartilha no contexto analisado? Diferentes audiências apresentam leques diferenciados de mídia em suas postagens?

A primeira pergunta se insere nas discussões acerca da provisão de informação política na web ou as formas como o cidadão se informa no ambiente digital. Afinal, em um contexto de proliferação de informações e canais de comunicação, são abundantes também os relatos que fazem referência a um ambiente de escolhas quase infinitas e de uma pluralização de vozes sem paralelos com acesso à esfera pública. Com tanto à disposição, questionamentos sobre pluralismo ou diversidade no ambiente midiático podem acabar sendo vistos como anacrônicos ou obsoletos. Em que medida, pergunta Karppinen (2009, p. 2), é razoável discutir diversidade midiática e pluralismo quando os sistemas de mídia como um todo estão caracterizados muito mais pela abundância que pela escassez?

De fato, muitos comentadores sustentam o impacto positivo da internet no que diz respeito à pluralidade midiática, com base no surgimento de novas fontes comerciais e não comerciais de notícias e das mídias sociais digitais. Uma análise mais cuidadosa, entretanto, sugere cautela. Gurevitch, 
Coleman e Blumler (2009), por exemplo, preferem a noção de "reconfiguração ecológica”, na qual a mídia de mainstream, inclusive tradicional, ainda ocupa um lugar dominante na provisão de notícias, em especial, a televisão, mas uma grande parte das pessoas também obtém hoje material político de blogs e outras mídias sociais, bem como de sites de governo, políticos e candidatos, além de outras fontes digitais alternativas.

Na mesma linha, Vargo (2011) mostra que a mídia tradicional, inclusive os jornais, permanece como a principal fonte de notícias compartilhadas nas mídias sociais, nos Estados Unidos. Newmann (2011), com um estudo desenvolvido na Grã-Bretanha, também concluiu que o conteúdo da mídia de mainstream domina as conversações nas mídias sociais, como destino final da maioria dos links compartilhados pelos usuários britânicos. Análises preliminares no âmbito desta pesquisa (Ituassu e Lifschitz, 2015) também confirmam a predominância no Brasil do compartilhamento de mídias de mainstream em postagens no Twitter.

Nesse debate, é preciso atentar para o papel dos "agregadores de notícias", entre os chamados "novos intermediários digitais" (Foster, 2012). Agregadores de notícias são aqueles sites que oferecem uma seleção de notícias, reportagens, matérias e outros materiais informativos produzidos por várias fontes diferentes, como é caso do G1, portal brasileiro de notícias que distribui conteúdo de diversas marcas do Grupo Globo, o maior do país e um dos maiores da América Latina. No G1, o usuário encontra conteúdos produzidos pela Rede Globo de Televisão, pelo canal a cabo de notícias Globo News, pela rádio all news $\mathrm{CBN}$, jornais O Globo e Diário de S. Paulo, revista Época, além de reportagens próprias do G1.

É também o caso do UOL, do Grupo Folha, que dirige o jornal Fotha de S. Paulo, um dos maiores do país. O UOL publica conteúdo próprio mas também de outras fontes, como da própria Folha. Outro exemplo de agregador digital brasileiro é o portal R7, do Grupo Record, que oferece notícias com o apoio da Rede Record, da Record News e afiliadas no país. Os agregadores de notícias seriam assim, segundo Foster (2012, p. 25), o que há de mais próximo da mídia tradicional entre os novos intermediários digitais de notícias. 
Com relação à segunda pergunta ("Diferentes audiências apresentam leques diferenciados de mídia compartilhada?”), trata-se de uma questão inspirada nos estudos mais recentes de agenda setting e também tem por base conclusões preliminares desta pesquisa. Nesse contexto, dialogamos aqui com a hipótese do agenda melding (Shaw e Weaver, 2014; Vargo et al., 2014), segundo a qual diferentes públicos misturam as agendas de várias mídias de modo distinto, isto é, se relacionam com diferentes leques de mídia e apresentam diferentes agendas de temas. Para os autores, a hipótese do agenda melding pergunta como audiências específicas selecionam e priorizam entre agendas da mídia, da nossa vida em comunidade, nossas referências mais próximas e nossas próprias convicções, a fim de criar uma visão confortável do mundo para nós mesmos (Shaw e Weaver, 2014). Mesmo que esta pesquisa não desenvolva de fato uma análise de agenda setting ou de agenda melding, dado que permanece no nível da escolha midiática feita pelo cidadão e não alcança questões relativas ao efeito dessas mesmas escolhas, acreditamos que uma abordagem sobre as preferências midiáticas que cada público distinto desenvolve no Twitter pode nos dar algumas pistas sobre a relação que cidadãos com diferentes posicionamentos políticos têm com a provisão de informação na internet.

Além disso, nossos primeiros resultados (Ituassu e Lifschitz, 2015) levantaram as hipóteses de que potenciais eleitores do candidato de oposição determinariam mais a dinâmica do compartilhamento de mainstream media, e potenciais eleitores da incumbente determinariam mais a dinâmica do compartilhamento de mídias sociais e complementares, o que supomos na ocasião poderia ser efeito do papel de "cão de guarda" (watchdog) do jornalismo brasileiro contemporâneo (Azevedo, 2010). Com uma amostra maior e um teste estatístico, no entanto, essa suposição não se confirmou.

Em suma, nossas perguntas de pesquisa (PPs) foram: PP1) Que fontes midiáticas foram compartilhadas no Twitter durante o segundo turno das eleições presidenciais de 2014 no Brasil? e PP2) Os diferentes públicos constituídos na disputa apresentam leques diferenciados de mídia compartilhada? 


\section{Metodologia}

O primeiro passo mais prático desta análise foi coletar os tweets publicados no segundo turno das eleições de 2014 no Brasil. A coleta dos dados foi feita a partir de uma interface de programação (Application Programming Interface - API), por meio da qual realizamos uma consulta ao Twitter para obter tweets com os termos escolhidos no período especificado. Com a consulta, obtivemos uma resposta no formato JSON, ${ }^{8}$ uma formatação de troca de dados, em uma taxa próxima de dois tweets por segundo. Os dados capturados foram: usuário que publicou o tweet, o texto publicado e a data no formato timestamp.

Durante a coleta dos dados, utilizamos o protocolo OAuth, ${ }^{9}$ um padrão aberto que permite acesso às ações dos usuários sem a necessidade de compartilhar suas senhas e logins. O protocolo estipula um fluxo de comunicação entre a aplicação solicitante (nós) e a aplicação servidora (o Twitter), e o fluxo de comunicação ocorreu em três etapas básicas: obtenção do token de requisição, autenticação e autorização pelo usuário e obtenção do token de acesso, que expira se não for usado.

Em nosso caso, o código da busca foi escrito na linguagem Python e possui apenas 56 linhas. Na programação, foi implementada a biblioteca Tweepy, ${ }^{10}$ por meio da qual podem ser realizadas pesquisas avançadas de consulta, definindo exatamente o que se deseja obter como resultado (por exemplo, tweets que contenham uma certa palavra ou hashtag, publicado em determinado período etc.). O programa se conecta com um banco de dados, e todos os resultados obtidos nas consultas são nele armazenados. Tal método é particularmente importante porque permite o acesso a tweets do passado, em casos nos quais o streaming não é mais possível, e seu armazenamento em planilhas de fácil manipulação (.csv). Assim, nos foi possível, no segundo semestre de 2016, a captura de mais de 200 mil tweets publicados entre 6 e 26 de outubro de 2014, dos quais extraímos uma amostra aleatória de 200 tweets por dia entre 13 e 23 do mesmo mês com a marca

8 Sobre isso, ver: http://json.org

9 Sobre isso, ver: https://dev.twitter.com/oauth

10 Sobre isso, ver: http://www.tweepy.org/ 
“\#Eleições2014", o que totalizou 2200 tweets para codificação manual. Em geral, os tweets destacados foram postados à noite, obedecendo aos horários considerados de pico no Twitter Brasil.

Sobre a hashtag utilizada, a escolha pelo indexador se deu por conta do seu uso por um grande número de veículos midiáticos, como se pode depreender da análise. Como uma das intenções desta pesquisa foi investigar que mídia foi compartilhada no Twitter no momento especificado, a hashtag nos foi de grande valia para a coleta de tweets que continham pelo menos um compartilhamento midiático, dado que a mensagem original do veículo já chegava ao usuário com a marca “\#Eleições2014”.

Como se sabe, as hashtags são um importante atributo que permitem a todos os usuários que desenvolvam suas discussões sobre tópicos específicos, isto é, com a inclusão do caractere "\#” em uma palavra ou frase para conectar todos os tweets relacionados ao tema (Oliveira, Bermejo e Santos, 2016, p. 2). Ao acompanhar um tema ou uma “\#”, o usuário terá contato com tweets de outros usuários que não necessariamente segue na mídia social.

Com relação ao período recortado, de 13 a 23 de outubro, dentro do contexto do segundo turno das eleições presidenciais de 2014 no Brasil, este representa, a nosso ver, o momento central da disputa, noção que pode ser reforçada pelas sondagens produzidas no momento. Segundo o Instituto Datafolha, nos dias 14 e 15 de outubro de 2014, Aécio Neves vencia Dilma Rousseff por uma diferença de 2 pontos percentuais, com uma margem de erro de valor equivalente. Entre 15 e 20 de outubro, no entanto, Dilma Rousseff teria ultrapassado o candidato da oposição, chegando a $52 \%$ dos votos. ${ }^{11}$

Com isso, a partir da amostra inicial de 2200 tweets, isto é, 200 tweets aleatórios por dia coletados no horário de pico do Twitter no Brasil e publicados entre 13 e 23 de outubro de 2014 com a marca \#Eleições2014 (Amostra A), um subconjunto de 1679 tweets foi produzido (Amostra B), com a exclusão de publicações originadas de contas relacionadas a empresas, or-

11 Sobre isso, ver: http://eleicoes.uol.com.br/2014/pesquisas-eleitorais/brasil/2-turno/ 
ganizações midiáticas e instâncias coletivas formais da sociedade civil e do Estado, no sentido de se isolar tweets com maior potencial de terem sido publicados por cidadãos. Com esse corpus em mãos, os tweets foram organizados em uma tabela com: 1) informações de identificação (nome e número do perfil, mantidos sempre sob sigilo); 2) data e hora da publicação; 3 ) o texto do tweet; 4) a identificação e a tipologia da mídia replicada, quando fora o caso, sendo as mídias classificadas como MP (mídia principal) e MC (mídia complementar), e 5) a suposta preferência eleitoral do usuário -ED: potencial eleitor de Dilma Rousseff, EA: potencial eleitor de Aécio Neves, e NDA: não identificado-.

Foram também desenvolvidas planilhas com o leque das mídias replicadas em geral e para cada tipo de potencial eleitorado, que definimos como "públicos", seguindo as noções de "público" de John Dewey e de "esfera pública” de Jürgen Habermas, como espaços autônomos de comunicação (Dewey, 2012 [1922]; Habermas, 1991). A codificação foi levada à frente por três pesquisadores entre os que assinam este trabalho, e as discrepâncias interpretativas foram resolvidas com base na busca por um consenso entre as três partes.

Com relação à análise de mídia, averiguamos primeiro se havia ou não um link embutido em cada mensagem. Quando positivo, identificamos que link seria este e o classificamos como MP ou MC. As categorias foram adaptadas da sugestão de Shaw et al. (2006) dos termos mídia vertical e mídia horizontal, que utilizamos anteriormente (Ituassu e Lifschitz, 2015). Nesta pesquisa específica, resolvemos usar os termos mídia principal e mídia complementar buscando uma alteração metodológica que pudesse tornar a qualificação mais precisa.

Nesse sentido, tomamos como referência para a codificação a Pesquisa Brasileira de Mídia 2014 (Brasil, 2014), que mapeou hábitos de consumo de mídia pela população brasileira. Com a pesquisa, foi possível listar as marcas midiáticas mais lembradas pelos entrevistados nos setores de televisão, rádio, jornal, internet e revista, o que nos forneceu um conjunto de 26 grandes mídias que caracterizamos como MPs: Rede Bandeirantes, Diário Gaúcho, 
revista Época, Jornal O Estado de São Paulo, jornal Extra, jornal Folha de S. Paulo, Rede Globo, jornal O Globo, Globo.com, portal Hoje em Dia (R7), IG, IstoÉ, Jornal do Brasil, Meia Hora, jornal O Dia, jornal O Povo, portal R7, Rede Record, Rede SBT, jornal Super Notícia, portal Terra, portal UOL, revista Veja, Yahoo e jornal Zero Hora. Todas as outras mídias encontradas — e foram catalogadas mais de 100 mídias nesta análise - foram classificadas como MCs, como um termo que procura adaptar para o ambiente web a noção de complementaridade apresentada por Dutta-Bergman, quando a autora ressalta a congruência no consumo de mídias tradicionais e on-line within a specific content domain (Dutta-Bergman, 2004, p. 41).

Se os termos principal e complementar denotam alguma hierarquia, nossa intenção é mais a de perceber uma "adição" de contextos informacionais diferenciados. Além disso, o termo complementar se refere a uma posição secundária da mídia no ambiente midiático, e não à importância que o cidadão poderia dar, individualmente, a esse tipo de mídia. Isto é, nada impede que um cidadão dê mais importância no seu dia a dia à leitura de uma MC em relação às MPs. A classificação aqui proposta apenas supõe que MCs ocupam um espaço menor na divisão de espaços no ambiente midiático brasileiro, em relação às MPs.

Ao mesmo tempo, apesar de a Pesquisa Brasileira de Mídia 2014 colocar as mídias sociais como o Facebook e o Twitter entre as mais lembradas pelos entrevistados no ambiente web, a sondagem oficial não leva em consideração as contas individuais nessas plataformas, mas a mídia em si, como um somatório de todas as suas contas. No entanto, quando o usuário se informa ou compartilha alguma postagem no Facebook ou no Twitter, não está compartilhando "o Facebook" ou "o Twitter", mas o conteúdo originado de contas específicas. Nesse sentido, quando olhadas a partir dessa perspectiva mais individual, tanto as mídias de alcance menor como as contas individuais encontradas nas mídias sociais (blogs, Facebook, Twitter, YouTube, Instagram etc.) foram qualificadas como MCs.

Com relação à identificação da preferência eleitoral, foi feita uma análise de sentimento do conteúdo postado, primeiramente a partir do reconhecimento de algum sinal mais explícito, como o uso de uma hashtag, por 
exemplo, \#Aécionever ou \#ForaDilma. No caso da não existência de sinal mais explícito, passamos para uma análise de sentimento da mensagem a partir dos seguintes parâmetros: a) tweets que continham mensagem (incluindo-se os links) tida como negativa a um dado candidato, campanha ou partido foram considerados como publicação de potencial eleitor do outro candidato, campanha ou partido. Da mesma forma, b) tweets com mensagem (incluindo-se os links) positiva a um dado candidato, campanha ou partido foram considerados como publicação de potencial eleitor do mesmo candidato, campanha ou partido.

Com isso, um usuário que compartilhou um link sobre um caso de corrupção que envolvia o PT, partido da então incumbente Dilma Rousseff, foi caracterizado como potencial eleitor de Aécio Neves. No mesmo sentido, um usuário que compartilhou algo sobre nepotismo na gestão de Aécio Neves como governador do estado de Minas Gerais foi qualificado como potencial eleitor de Dilma Rousseff. Quem, no contexto acirrado do segundo turno das eleições de 2014 no Brasil, compartilhou link ou matéria sobre algum apoio público importante dado a Aécio Neves foi considerado potencial eleitor do candidato. Quem compartilhou conteúdo midiático sobre os efeitos positivos dos programas sociais do governo Dilma Rousseff foi qualificado como potencial eleitor da incumbente.

Como se percebe, trata-se de uma aproximação que pretendemos deixar clara com o uso da expressão potencial eleitor. Todo o pressuposto é o de que um potencial eleitor de um candidato, em um contexto altamente polarizado e disputado, tenderia a não compartilhar algo que poderia ser visto como negativo para o mesmo candidato, bem como a compartilhar algo que poderia ser visto como positivo para ele.

Assim, com base em ambas as classificações, potencial eleitor de Aécio Neves (EA) e potencial eleitor de Dilma Rousseff (ED), para preferência eleitoral, e mídia principal (MP) e mídia complementar (MC), para mídia compartilhada, foi então desenvolvida uma análise quantitativa, com o cruzamento das variáveis e o teste estatístico (Qui-quadrado), com resultados sobre a relação entre os dois públicos distintos e suas escolhas midiáticas. 
Nesse sentido, a partir dos procedimentos metodológicos descritos, outros dois subconjuntos de amostras foram produzidos. Um que chamamos de "Amostra C", com todos os tweets nos quais ocorreu pelo menos um compartilhamento de mídia, com a exclusão dos tweets que não compartilharam mídia, e outro (Amostra D) com todos os tweets nos quais também foi possível identificar a preferência eleitoral. A Tabela 1 a seguir resume as quatro amostras. As análises somente de mídia foram feitas com base na Amostra C, aquelas que envolviam compartilhamento de mídia e preferência eleitoral foram desenvolvidas com base na Amostra D.

\section{Tabela 1. Conjunto de amostras}

\begin{tabular}{|c|l|l|l|}
\hline \multicolumn{1}{|c|}{ Amostra A } & \multicolumn{1}{c|}{ Amostra B } & \multicolumn{1}{c|}{ Amostra C } & \multicolumn{1}{c|}{ Amostra D } \\
\hline $\begin{array}{l}\text { 200 tweets por dia } \\
\text { coletados aleatoriamente } \\
\text { em horário de pico durante } \\
\text { dez dias. }\end{array}$ & $\begin{array}{l}\text { Foram excluídos tweets } \\
\text { de empresas, organizações } \\
\text { midiáticas etc. }\end{array}$ & $\begin{array}{l}\text { Foram excluídos os tweets } \\
\text { que não continham } \\
\text { compartilhamento de } \\
\text { mídia. }\end{array}$ & $\begin{array}{l}\text { Foram excluídos os tweets em } \\
\text { que não foi possível identificar } \\
\text { preferência eleitoral. }\end{array}$ \\
\hline 2200 & 1679 & 1439 & 1129 \\
\hline
\end{tabular}

Fonte: elaborada pelos autores.

\section{Resultados, novas hipóteses}

$\mathrm{O}$ primeiro resultado encontrado da amostra diz respeito à preponderância das grandes mídias no compartilhamento de mídia, que se confirma como uma tendência do espaço analisado. Dos 2200 tweets da Amostra A, em 1439 tweets, houve algum compartilhamento de mídia (65,4\%), como deduzimos da Amostra C. De todos os links compartilhados, $59 \%$ se referiram a alguma das mídias principais no país, e 41 \%, a mídias sociais e complementares, transparecendo algo como uma divisão de espaços na comunicação indexada pela hashtag, como mostra a Tabela 2 a seguir.

\section{Tabela 2. Mídia compartilhada}

\begin{tabular}{|c|c|c|}
\hline MP & 851 & $59 \%$ \\
\hline MC & 588 & $41 \%$ \\
\hline Total & 1439 & $100 \%$ \\
\hline
\end{tabular}

MP: Mídia Principal

MC: Mídia Complementar

Fonte: elaborada pelos autores. 
Na mesma linha, percebe-se da amostra um grupo de dez mídias entre as mais compartilhadas, que corresponde a $60 \%$ dos compartilhamentos (Tabela 3). Outras mais de cem mídias dividiram os $40 \%$ restantes.

Tabela 3. As mídias mais compartilhadas (\%)

\begin{tabular}{|l|c|}
\hline G1 & 15 \\
\hline UOL & 15 \\
\hline Folha & 5 \\
\hline Estadão & 5 \\
\hline Valor & 5 \\
\hline Jornal do Brasil & 4 \\
\hline O Dia & 3 \\
\hline O Globo & 3 \\
\hline R7 & 3 \\
\hline A Tarde & 2 \\
\hline Total & 60 \\
\hline
\end{tabular}

Fonte: elaborada pelos autores.

A partir da classificação sugerida por Foster (2012) e Newman e Levy (2012) - a) websites de empresas de TV e rádio, jornais e revistas (old media in the $(W e b)$; b) agregadores digitais de notícias, e c) mídias sociais digitais-, percebe-se novamente um predomínio da mídia de mainstream, considerando, como sugere Foster (2012, p. 25), que os agregadores de notícias seriam, entre os intermediários digitais, o que há de mais próximo da mídia tradicional. Entre as 20 mídias mais compartilhadas na amostra, um terço é de portais e websites de empresas de TV, rádio, jornais e revistas, outro terço é de agregadores digitais, e o terço final, mídias sociais. Por esse viés, a chamada "mídia tradicional" ou mídia de mainstream acabaria correspondendo a dois terços dos compartilhamentos.

Entretanto, além de confirmar o predomínio da mídia de mainstream, esta pesquisa gostaria de sugerir a ideia de "mídias sociais como mídias complementares" (social media as complementary media). Afinal, ao menos no contexto analisado, as mídias sociais dominaram o espaço das mídias complementares. Como se vê na Tabela 4 a seguir, as seis mídias mais compartilhadas, entre as MCs, são mídias sociais populares no Brasil. 


\section{Tabela 4. Mídias mais compartilhadas entre as MCs (\%)}

\begin{tabular}{|l|c|}
\hline Twitter & 29 \\
\hline Facebook & 20 \\
\hline Blogs & 12 \\
\hline Instagram & 8 \\
\hline YouTube & 7 \\
\hline Congresso em foco & 1 \\
\hline Brasil Post & 1 \\
\hline Eleições2014.com.br & 1 \\
\hline Brazil Wire & 1 \\
\hline Jornalismo Wando & 1 \\
\hline Reuters & 1 \\
\hline Outros (74) & 18 \\
\hline Total & 100 \\
\hline
\end{tabular}

Fonte: elaborada pelos autores.

Com relação à pergunta se diferentes audiências políticas apresentariam leques diferenciados de mídias, percebe-se, pela Tabela 5, composta das 15 mídias mais compartilhadas por cada um dos potenciais eleitorados, que os dois públicos apresentam opções bastante semelhantes. Em ambos os públicos, aparecem os portais G1 e UOL, as versões on-line dos jornais Folha de S. Paulo (Folha), Jornal do Brasil (JB), Estado de São Paulo (Estadão), Valor e A Tarde, bem como as mídias sociais Facebook, Twitter, blogs, YouTube e Instagram. Apenas 3 das 16 mídias mais compartilhadas pelos dois eleitorados apareceram em somente uma das audiências: o jornal O Globo e a revista Veja, de perfil mais conservador, foram compartilhados somente por potenciais eleitores de Aécio Neves, e o jornal O Dia, de perfil mais popular, foi compartilhado somente por eleitores de Dilma Rousseff.

Apesar das similitudes, é possível perceber que as diferentes audiências mostraram opções bastante diferenciadas de MCs quando olhamos mais detalhadamente as contas e os perfis específicos que cada um dos públicos compartilhou, como se vê na Tabela 6. Da nossa perspectiva, esse papel das mídias sociais reforça a ideia de social media as complementary media, de modo que as mídias de mainstream, pelo menos teoricamente mais neutras, são complementadas por informações mais partidarizadas a cada 
um dos eleitorados. Não à toa, boa parte do conteúdo de mídias sociais compartilhado parece nitidamente material patrocinado de ambas as campanhas, que disputam a atenção do cidadão com suas estratégias de comunicação política digital.

\section{Tabela 5. As 15 mídias mais compartilhadas por cada um dos públicos (\%)}

\begin{tabular}{|l|c|l|c|}
\hline Potenciais eleitores de Aécio Neves & $\%$ & Potenciais eleitores de Dilma Rousseff & $\%$ \\
\hline G1 & 17 & G1 & 15 \\
\hline Twitter & 12 & UOL & 9 \\
\hline Facebook & 9 & Twitter & 8 \\
\hline UOL & 8 & O Dia & 8 \\
\hline JB & 5 & Valor & 7 \\
\hline O Globo & 5 & Estadão & 7 \\
\hline R7 & 4 & Folha & 5 \\
\hline Folha & 4 & Facebook & 5 \\
\hline Estadão & 4 & Blogs & 4 \\
\hline Valor & 3 & JB & 3 \\
\hline Blogs & 2 & Época & 2 \\
\hline YouTube & 2 & Instagram & 2 \\
\hline Veja & 2 & Terra & 2 \\
\hline A Tarde & 1 & YouTube & 2 \\
\hline Instagram & 1 & A Tarde & \\
\hline
\end{tabular}

Fonte: elaborada pelos autores.

Por fim, ao contrário do que sugeriram nossas análises anteriores e a partir do aumento da amostra e da consequente possibilidade de se desenvolver um teste estatístico (Qui-Quadrado - Tabela 7), foi possível perceber que os públicos distintos apresentaram praticamente o mesmo padrão relativo de compartilhamento de mídias principais e complementares $(\mathrm{p}=0.021)$. Como será possível ver a seguir (Gráfico 1$)$, ambas as audiências apresentaram percentuais bastante semelhantes de compartilhamento de MPs (61 \% e $67 \%$ ) e de MCs (39\% e $33 \%)$.

A nosso ver, é possível depreender dos números uma ampla capacidade do core midiático brasileiro de servir de referência para eleitores tanto da incumbente como da oposição, ao contrário da suposição de que a mídia 
de mainstream pudesse estar mais relacionada ao eleitorado do candidato oposicionista. Além disso, os achados levantam a possibilidade de um padrão de comportamento que complementa a oferta de informações originadas dos principais conglomerados midiáticos com outras mais horizontais e partidarizadas.

\section{Tabela 6. Mídias complementares compartilhadas por cada um dos potenciais eleitorados}

\begin{tabular}{|l|l|}
\hline \multicolumn{1}{|c|}{ Potenciais eleitores de Aécio Neves } & \multicolumn{1}{|c|}{ Potenciais eleitores de Dilma Rousseff } \\
\hline Blog do Reinaldo Azevedo (Veja) & Brasil 247 \\
\hline Blog da Miriam Leitão (O Globo) & Blog Conversa Afiada (Paulo H. Amorim) \\
\hline Blog do Noblat (O Globo) & Blog do Aílton \\
\hline Blog do Ricardo Setti (Veja) & Blog do Miro \\
\hline Blog do Rodrigo Constantino (Veja) & Blog José Roberto de Toledo \\
\hline Blog Pastor Everaldo & Blog Julia Duailib (Estadão) \\
\hline Congresso em foco & Blog da Laura Capriglione (Yahoo) \\
\hline Twitter do Olavo de Carvalho & Pragmatismo político \\
\hline
\end{tabular}

Fonte: elaborada pelos autores.

Tabela 7. Teste Qui-quadrado

\begin{tabular}{|c|c|c|}
\hline \multirow{2}{*}{ EA } & MP & MC \\
\hline \multirow{2}{*}{ ED } & 353 & 228 \\
\cline { 2 - 3 } & 371.5518158 & 209.4481842 \\
\cline { 2 - 3 } & 0.926 & 1.643222019 \\
\cline { 2 - 3 } & 369 & 179 \\
\cline { 2 - 3 } & 350.4481842 & 197.5518158 \\
\hline Qui-quadrado & 0.982084895 & 1.74217517 \\
\hline DF & 369.000 & \\
\hline p-value & 1 & \\
\hline $\mathrm{n}$ & $\mathbf{0 . 0 2 1}$ & \\
\hline & 1129 & \\
\hline
\end{tabular}

EA: potencial eleitor de Aécio

ED: potencial eleitor de Dilma

MP: Mídia Principal

MC: Mídia Complementar

Valores observados, esperados, Qui-quadrado.

Fonte: elaborada pelos autores. 


\section{Gráfico 1. \% de MP e MC para cada público}

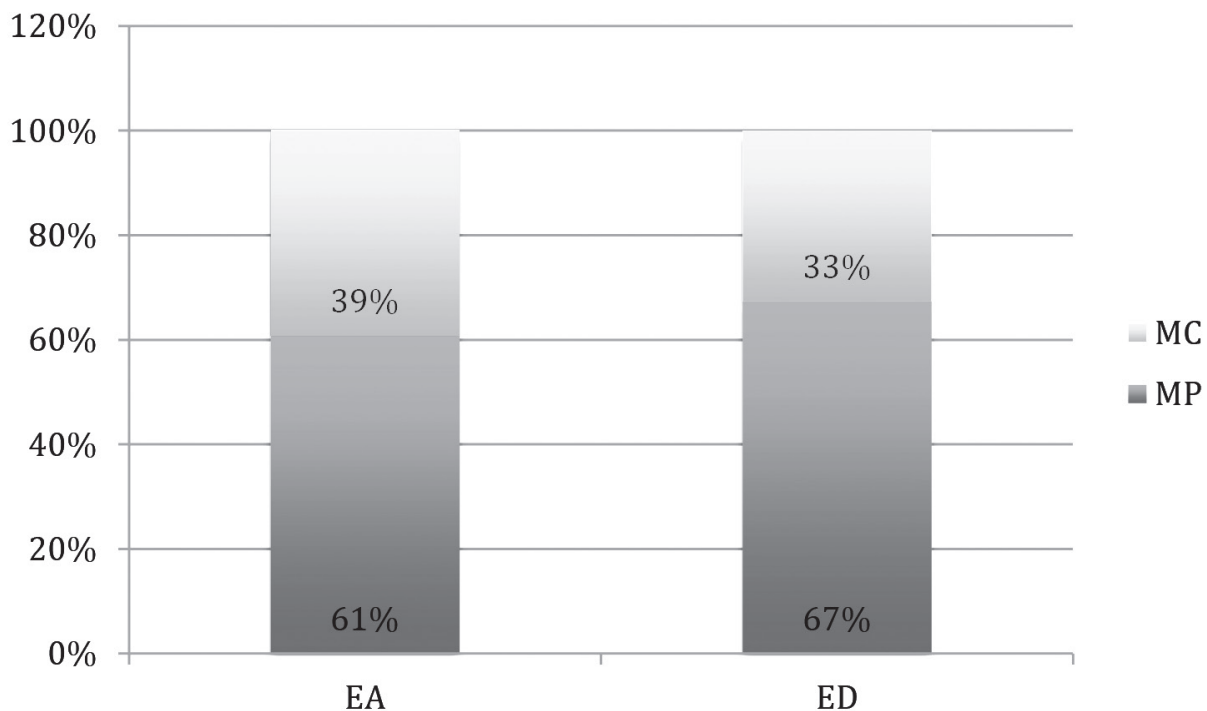

EA: potencial eleitor de Aécio Neves

ED: potencial eleitor de Dilma Rousseff

MP: Mídias Principais

MC: Mídias Complementares

Fonte: elaborado pelos autores.

\section{Considerações finais}

O primeiro ponto a ser ressaltado em uma seção de conclusões em um trabalho como este é o fato de que é preciso cautela para não generalizar os achados desta pesquisa, que analisa uma amostra relativamente pequena para estudos desse tipo e que está restrita não somente ao Twitter, mas também a um contexto eleitoral específico bastante polarizado. Com relação ao tamanho da amostra, trata-se de um conjunto de dados certamente pequeno, por exemplo, em relação aos mais de 200 mil coletados somente ao longo do segundo turno das eleições presidenciais de 2014 e que só podem ser alvo, ao menos em sua totalidade, de análises automatizadas. Entretanto, se uma amostra reduzida exige cautela no que diz respeito a generalizações, ela também permite uma análise manual mais precisa, que pode servir de base para o desenvolvimento de ferramentas de automação (machine learning). Além disso, o fato de a análise ter sido levada à frente sobre dados de 2014 também faz com que os seus achados sejam vistos com cuidado, 
dada a velocidade na qual as transformações no ambiente digital se desenvolvem, incluindo-se aí os hábitos de consumo de mídia.

Apesar disso, este trabalho traz pelo menos quatro sugestões de conclusão que devem servir como hipóteses para futuros testes. A primeira diz respeito à PP1 ("Que fontes midiáticas foram compartilhadas no Twitter durante o segundo turno das eleições presidenciais de 2014 no Brasil?") e ao papel hegemônico da mídia de mainstream como referência principal do conteúdo compartilhado, o que já vem sendo confirmado por outros estudos (Foster, 2012; Newman, 2011; Vargo, 2011). Como foi visto, somando-se os agregadores digitais aos veículos tradicionais em sua versão web, percebe-se que aproximadamente dois terços do conteúdo compartilhado podem ser considerados de mídias principais. Ao confirmar a hegemonia da mídia de mainstream no ambiente analisado, este estudo corrobora a sugestão de Karppinen (2009) de que novas hierarquias se consolidam no espaço-tempo digital, e a existência da web em si não é elemento suficiente para se esgotar as discussões, muito menos as potenciais regulações, no que diz respeito à pluralidade do ambiente midiático.

No mesmo sentido e como desdobramento dos resultados encontrados, propomos aqui a noção de "mídias sociais como mídias complementares", com o papel de oferecer conteúdo midiático de nicho e mais partidarizado, se aproximando dos interesses de seus públicos específicos e com uma configuração de produção que não se configura no modelo clássico industrial. A grande parte desse tipo de conteúdo compartilhado na amostra analisada foi de contas específicas de mídias sociais como determinados blogs, contas no Twitter e canais de YouTube de jornalistas e analistas políticos conhecidos por suas posições mais partidárias, bem como de materiais de campanha distribuídos pela militância ao redor de cada uma das candidaturas.

As segunda e terceira sugestões de conclusão se referem à PP2 ("Os diferentes públicos constituídos na disputa apresentam leques diferenciados de mídia compartilhada?") e indicam que o formato do compartilhamento de mídia em relação às tipologias analisadas (MP e MC) se mostrou independente da preferência eleitoral e que as MCs, especialmente as mídias sociais, servem de referência mais próxima ao posicionamento político 
de cada um dos públicos. A nosso ver, a independência das variáveis analisadas demonstra a força e a penetração do core midiático brasileiro sobre audiências de perfil político diferenciado, mesmo que alguns estudos tentem identificar um viés contrário de uma boa parte desse mesmo core a um dos lados mais especificamente. ${ }^{12}$

Nesse contexto, os resultados apresentados aqui reafirmam conclusões anteriores (Ituassu e Lifschitz, 2015) de que ambas as audiências apresentam um compartilhamento de mídia bastante semelhante, diferindo somente no conteúdo detalhado das mídias complementares compartilhadas. Diferentes audiências políticas, como foi visto, apresentariam diferentes opções de mídias complementares, mais identificadas politicamente com seus próprios públicos específicos. Algo que, do nosso ponto de vista, pode ser tratado como uma hipótese relativa à contribuição do ambiente digital à ecologia da mídia no Brasil em contexto de eleições e como um possível padrão na escolha de fontes de informação política por públicos específicos no ambiente digital.

\section{Referências}

Azevedo, F. (2010). Corrupção, mídia e escândalos midiáticos no Brasil. Debate, 2(3), 14-19.

Brasil, Presidência da República. (2014). Pesquisa Brasileira de Mídia 2014. Secom. Recuperado em http://www.secom.gov.br/atuacao/pesquisa/lista-total-de-pesquisas/relatorio-final-pesquisa-brasileirade-midia-2014.pdf

Brasil, Presidência da República. (2015). Pesquisa Brasileira de Mídia 2015. Secom. Recuperado em http://www.secom.gov.br/atuacao/pesquisa/lista-de-pesquisas-quantitativas-e-qualitativas-de-contratos-atuais/pesquisa-brasileira-de-midia-pbm-2015.pdf

Dewey, J. (2012[1922]). The Public and its Problems: An Essay in Political Inquiry. Pennsilvania: The Pennsilvania State University Press.

12 Sobre isso, por exemplo, ver o site Manchetômetro: http://www.manchetometro.com.br 
Dutta-Bergman, M. J. (2004). Complementary in Consumption of News Types Across Traditional and New Media. Journal of Broadcasting \& Electronic Media, 48(1), 41-60.

Foster, R. (2012). News Plurality In a Digital World. Reuters Institute for the Study of Journalism. Recuperado em http://reutersinstitute. politics.ox.ac.uk/sites/default/files/News\%20Plurality\%20in\%20 a\%20Digital\%20World_0.pdf

Gomes, W., Fernandes, B., Reis, L. e Silva, T. (2009). "Politics 2.0": a campanha on-line de Barack Obama em 2008. Revista de Sociologia e Política, 17(34), 29-43.

Gurevitch, M., Coleman, S. e Blumler, J. G. (2009). Political Communication: Old and New Relationships. Annals, AAPSS, vol. 625. doi: 10.1177/0002716209339345

Habermas, J. (1991). The Structural Transformation of the Public Sphere: An Inquiry Into a Category of Bourgeois Society. Cambridge, MA: MIT Press.

Ituassu, A. e Lifschitz, S. (2015) Temas e mídia em \#Eleições2014: Twitter, opinião pública e comunicação política no contexto eleitoral brasileiro. E-Compós, 18(2), 1-19.

Ituassu, A., Capone, L., Parente, T. e Pecoraro, C. (2014). Internet, eleições e democracia: o uso das redes sociais digitais por Marcelo Freixo na campanha de 2012 para a Prefeitura do Rio de Janeiro. Compolítica, 4(2), 59-86. doi: http://dx.doi.org/10.21878/compolitica.2014.4.2.152

Karppinen, K. (2009). Rethinking Media Pluralism and Communicative Abundance. McGannon Center Research Resources. Recuperado em http: //fordham.bepress.com/cgi/viewcontent.cgi?article $=1008$ \&context=mcgannon_research 
Muñiz, C., Dader, J. L., Téllez, N. M. e Salazar, A. (2016). ¿Están los políticos políticamente comprometidos? Análisis del compromiso político 2.0 desarrollado por los candidatos a través de Facebook. Cuadernos.info, (39), 135-150. doi: 10.7764/cdi.39.970

Murta, F., Ituassu, A, Capone, L. e Rovere, R. L. (2017). Eleições e mídias sociais: interação e participação no Facebook durante a campanha para a Câmara dos Deputados em 2014. Revista Compolítica, 7(1), 47-72. doi: http://dx.doi.org/10.21878/compolitica.2017.1.1.275

Newman, N. (2011). Mainstream media and the distribution of news in the age of social discovery. Reuters Institute for the Study of Journalism. Recuperado em http://reutersinstitute.politics.ox.ac.uk/sites/default/files/Mainstream\%20media\%20and\%20the\%20distribution\%20of\%20news\%20in\%20the\%20age\%20of\%20social\%20 discovery_0.pdf

Newman, N. e Levy, D. (2012). Digital News Report 2012. Reuters Institute for the Study of Journalism. Recuperado em http:// reutersinstitute.politics.ox.ac.uk/sites/default/files/Digital\%20News\%20Report\%202012.pdf

Newman, N., Levy, D. e Nielsen, K. (2015). Digital News Report 2015. Reuters Institute for the Study of Journalism, 2015. Recuperado em http://reutersinstitute.politics.ox.ac.uk/publication/digital-newsreport-2015

O'connor, B., Balasubramanyan, R., Routledge, B. e Smith, N. A. (2010). From Tweets to Polls: Linking Text Sentiment to Public Opinion Series. Proceedings of the Fourth International AAAI Conference on Webblogs and Social Media.

Oliveira, D. J. S., Bermejo, P. H. S. e Santos, P. A. (2016). Can social media review the preferences of voters? A comparison between sentiment analysis and traditional opinion polls. Journal of Information Technology \& Politics. doi: 10.1080/19331681.2016.1214094 
Pew Research Center. (2015). State of the News Media 2015. Pew Research Center. Recuperado em http://www.journalism.org/2015/04/29/ state-of-the-news-media-2015

Rosentiel, T., Sonderman, J., Loker, K., Ivancin, M. e Kjarval, N. (2015). Twitter and the News: How people use the social network to learn about the world. American Press Institute. Recuperado em http:// www.americanpressinstitute.org/publications/reports/survey-research/how-people-use-twitter-news

Shaw, D. e Weaver, D. H. (2014). Media Agenda-Setting and Audience Agenda-Melding. Em M. E. McCombs (org.), Setting the Agenda: Mass Media and Public Opinion (pp. 4562-4673). Cambridge: Polity Press, Kindle Edition. Pos 4562-4673

Tumasjan, A., Sprenger, T. O., Sandner, P.G. e Welpe, I. M. (2010). Predicting elections with Twitter: What 140 Characters Reveal about Political Sentiment. Proceedings of the Fourth International AAAI Conference on Weblogs and Social Media.

Vaccari, C. e Nielsen, R. K. (2013). Do people "like" politicians on Facebook? Not really. Large-Scale Direct Candidate-to-Voter Online Communication as an Outlier Phenomenon. Journal of Information Technology and Politics, 7, 2333-2356.

Vargo, C. J. (2011). National Television News and Newspapers as Media Salience, Twitter as Public Salience: An Agenda-Setting Effects Analysis. Tese apresentada para a obtenção do título de Mestre no Departamento de Advertising \& Public Relations na Graduate School of The University of Alabama.

Vargo, C. J., Guo, L., McCombs, M. E. e Shaw, D. (2014). Network Issue Agendas on Twitter During the 2012 U.S. Presidential Election. Journal of Communication, 64(2), 296-316. doi: 10.1111/ jcom.12089 